\title{
AgE AND SEX-SPECIFIC RATES OF LEAF REgENERATION IN THE MoJave Desert Moss Syntrichia CANINERVIS ${ }^{1}$
}

\author{
Lloyd R. Stark,,$^{2,4}$ Lorenzo Nichols II, ${ }^{2}$ D. Nicholas McLetchie, ${ }^{3}$ \\ STANLEy D. SMITH, ${ }^{2}$ AND Christopher ZundeL ${ }^{2}$
}

\author{
${ }^{2}$ Department of Biological Sciences, University of Nevada, 4505 Maryland Parkway, Las Vegas, Nevada 89154-4004 USA; and \\ ${ }^{3}$ Department of Biology, 101 Morgan Building, University of Kentucky, Lexington, Kentucky 40506-0225 USA
}

\begin{abstract}
The extremely skewed female-biased sex ratio in the desert moss Syntrichia caninervis was investigated by assessing the regeneration capacity of detached leaves. Juvenile, green, yellow-green, and brown leaves equating to approximately 0, 2, 6, and 12 yr of age, respectively, were detached from individuals of $S$. caninervis collected from 10 field populations and grown in a growth chamber for $58 \mathrm{~d}$ at a light intensity of 33-128 $\mu \mathrm{mol} \cdot \mathrm{m}^{-2} \cdot \mathrm{s}^{-1}$. Younger leaves $(0-2 \mathrm{yr}$ old $)$ tended to have a greater viability, regenerate more quickly, extend their protonemal filaments farther, produce shoots (gametophores) more quickly, produce more shoots, and accumulate a greater biomass than older leaves ( 6 and $12 \mathrm{yr}$ old). Among younger leaf classes, regenerating female leaves were more likely to produce a shoot than male leaves and produced more shoots than male leaves. The sexes did not differ significantly in time until protonemal emergence, linear extension of protonemata, or rate of biomass accumulation. However, protonemata of male leaves tended to emerge more quickly and produce a greater total biomass, ultimately consisting mostly of protonemata, than did female leaves. The more rapid proliferation of shoots by female leaf regenerants may help to explain the rarity of males in this species.
\end{abstract}

Key words: bryophyte; desert; leaf age; leaf regeneration; Mojave Desert, Nevada; sex dimorphism; sex ratio.

Unlike seed plants, all bryophytes are capable of significant clonal expansion through gametophytic growth, fragmentation, and in many cases production of specialized asexual propagules (During, 1990; Newton and Mishler, 1994). In the case of fragmentation and propagule production, clonal expansion or establishment occurs when these structures germinate, producing secondary protonemata and eventually shoots (gametophores).

In bryophytes that do not commonly undergo sexual reproduction (e.g., many dioecious species), propagation in nature is assumed to be mostly clonal, and in desert species, a skewed sex ratio translates into a rarity of mixed-sex patches (Bowker et al., 2000). Dustdevils, high winds, and animal disturbances in the Mojave Desert may lead to detachment of leaves, not unlike the strong, sustained winds in the arctic that result in a high concentration of fragmented moss leaves and stems in snowbeds (Miller and Ambrose, 1976). The latter study found that only in Tortula were detached leaves found among the fragments, although none of these leaves regenerated in culture. Although leaf regeneration in bryophytes has not been widely studied, several studies have confirmed that most moss-

\footnotetext{
${ }^{1}$ Manuscript received 17 April 2003; revision accepted 14 August 2003.

The authors thank Lynn Fenstermaker, Eric Knight, and Derek Babcock for assistance at the Nevada Test Site, Peter Starkweather for use of his laboratory equipment, and Stephanie Freer for translating critical German articles. The research was funded by a seed grant from the Interdisciplinary Science of Nevada's Unique Environments Program through the National Science Foundation EPSCoR (Experimental Program to Stimulate Competitive Research); a New Investigator Award; and a Stimulation, Implementation, Transition and Enhancement Award from the University of Nevada, Las Vegas Office of Research. Ongoing discussions with Brent Mishler, Mel Oliver, Mary Bonine, and Clayton Newberry were very helpful. Joseph Martel and Matt Peers assisted with the growth chamber arrangements. The second author (L. N.) was funded by an EPSCoR summer fellowship, a McNair scholarship, and a WAESO scholarship (Western Alliance to Expand Student Opportunities). Materials and supplies were funded in part by WAESO. S. D. S. was funded by the Department of Energy, Program for Environmental Research.

${ }^{4}$ E-mail: LRS@UNLV.nevada.edu.
}

es and liverworts are capable of efficient regeneration from leaves (e.g., Kumar et al., 2000).

One longstanding phenomenon that has yet to be adequately explained is the prevalence of female-biased sex ratios among dioecious bryophytes (Longton, 1990; Wyatt, 1994). Given that the sex ratio at meiosis is expected to be 19 : $10^{\text {t }}$ due to sex chromosomes (Ramsay and Berrie, 1982), reproduction via spores should result in offspring with unbiased sex ratios. While deviations in adult sex ratios are expected, observed deviations cannot be explained solely on the basis of random demographic processes or sex-specific survival differences. Adult sex ratio patterns are distinctively variable, with sex

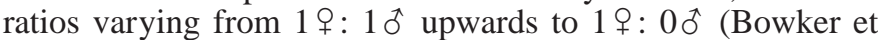
al., 2000). Regions of extreme climate, such as polar or desert sites, tend to have more highly skewed sex ratios (Longton, 1990; Stark et al., 1998), prompting the hypotheses that female plants are able to tolerate extreme temperatures (Une, 1985a) or desiccation stress (Newton, 1972) to a greater extent than males.

Adult population sex ratios can also be affected by sexspecific life history patterns, including survival and clonal expansion. In some seed plants, a higher rate of clonal expansion in males relative to females is associated with male-biased sex ratios (Putwain and Harper, 1972; Lovett Doust and Lovett Doust, 1988; Popp and Reinartz, 1988; Escarre and Houssard, 1991; Korpelainen, 1992; Eppley et al., 1998; but see Grant and Mitton, 1979; Sakai and Burris, 1985; Williams, 1995). However, in bryophytes this expected association between greater clonality of females and female-biased sex ratios is less evident. Relative to males, a higher capacity for clonal expansion (Newton, 1972) and survival (McLetchie, 1992) in females is known in some species. However, in some instances the direction of the dimorphic feature runs opposite to the prediction, in that males are reported to have higher clonal expansion capacities than females (Voth and Hamner, 1940; Longton and Greene, 1979). In several species, the patterns are mixed-females have higher clonal capacities in one trait and males in another (Shaw and Gaughan, 1993; McLetchie 
and Puterbaugh, 2000). Finally, a lack of sex-specific life history traits is also known (Longton and Greene, 1979). Recently, a simulation model on sex-ratio dynamics using a bryophyte model system demonstrated the connection between sexspecific life histories and local population sex ratios (McLetchie et al., 2002). Thus, the investigation of potential sex-specific regeneration rates is important in understanding population sex ratios given the dependence of this sex ratio on sex-specific life history traits in both seed plants and bryophytes (McLetchie et al., 2002 and references therein).

Plants of Syntrichia caninervis Mitt. [also known as Tortula caninervis (Mitt.) Broth.] are not known to produce specialized asexual reproductive propagules (Flowers, 1973; Gallego, 2002). Therefore, given the rarity of sexually reproducing populations (Stark et al., 1998), they rely on fragmentation of stems and leaves and subsequent regeneration of these fragments to colonize new substrates. The sex ratio of this species has been estimated from two localities in southern Nevada, ranging from 1우 $00^{\hat{\gamma}}$ at low elevations (Stark et al., 1998) to 6: $1 \mathrm{o}^{\hat{x}}$ in mixed-sex patches at higher elevation (Stark et al., 2001). Regeneration rates in bryophytes as a function of leaf age have been documented in several species, with the general consensus that the younger, apical leaves tend to regenerate more quickly and remain viable longer than more proximal leaves (e.g., Longton and Greene, 1979). However, to our knowledge, regeneration rates in bryophytes as a function of leaf sex have rarely been studied.

Could sex ratio patterns in S. caninervis reflect sex-specific rates of regeneration? In this paper, we explore potential sexspecific regeneration rates in this desert moss and pose the following two hypotheses:

1. Detached female leaves exhibit more vigorous leaf regeneration in some traits, given that they are the majority sex. We predict that female detached leaves will produce protonemata before males, produce secondary protonemata that extend farther from the original leaf, produce more shoots, and accumulate more biomass than detached male leaves. However, male detached leaves are likely to have higher capacities in at least one of these traits (based on McLetchie et al., 2002).

2 . Younger leaves of both sexes regenerate more efficiently than older leaves. We predict that juvenile and younger distal leaves will begin to regenerate earlier, produce secondary protonemata that extend farther from the original leaf, produce more shoots, and accumulate more biomass over a similar time period than older, more proximal leaves.

\section{MATERIALS AND METHODS}

Population sampling and detection of sex-On 29 May 2002, a series of sporophytic patches from a single metapopulation (sensu Husband and Barrett, 1996) of Syntrichia caninervis was collected from the northern Mojave Desert: Nevada Test Site, Frenchman Flat, adjacent to the Mojave Global Change Facility (a study site investigating effects of global change on Mojave Desert vegetation; $\left.115^{\circ} 59^{\prime} 24^{\prime \prime} \mathrm{W}, 36^{\circ} 45^{\prime} 36^{\prime \prime} \mathrm{N}\right)$. Sporophytic patches were intentionally targeted because the presence of sporophytes indicates that both sexes are likely to be present (Bowker et al., 2000). At this site, S. caninervis represents the dominant moss in the landscape. These patches (defined as a series of more or less contiguous clumps of stems separated from other such series) were physically separated from one another by at least $5 \mathrm{~m}$. Ten of these patches were examined for sex expression by removing stems in the neighborhood of sporophytic plants, hydrating them on a microscope slide, and nonintrusively probing among the leaves to find inflorescences. Twentyfive stems of each sex were isolated from each patch, the sex confirmed, and two stems of each sex per patch randomly selected for the experiment. In one patch, we were able to find only one stem of each sex, so we added a second stem of each sex from one of the other patches. In all, 20 female and 20 male stems (ramets) were used in the experiment. No sexually dimorphic morphological features were obvious during the dissections. To estimate initial leaf biomass, 10 individuals were randomly selected (one per patch), hydrated, and up to five leaves of each age class were detached from each stem. These groups of leaves were dried to constant mass at $40^{\circ} \mathrm{C}$ for $3 \mathrm{~d}$ and weighed to the nearest microgram.

Leaf position and approximating leaf age-One leaf of each age class (juvenile, green, yellow-green, brown; Fig. 1) was isolated from each stem as follows, using a dissecting microscope (Leica MZ6, McBain Instruments, Chatsworth, California, USA). These age classes corresponded roughly to these Munsell colors (Wilde and Voigt, 1977): 2.5GY8/10 (juvenile), 2.5GY7/ 10 to $5 \mathrm{Y} 8 / 12$ (green), $5 \mathrm{Y} 7-8 / 10$ (yellow-green), $2.5 \mathrm{Y} 7 / 8$ to $7.5 \mathrm{YR} 6 / 8$ to $6 /$ 10 (brown). The stem was hydrated, and, working from the stem base to the stem apex, one leaf was selected from the first group of brown leaves, first group of yellow-green leaves, the first group of full-sized green leaves, and a juvenile leaf from the tightly appressed apical meristematic region. A juvenile leaf was considered to be an unexpanded leaf. The distance, to the nearest $0.5 \mathrm{~mm}$, was measured from the point of leaf attachment to the shoot apex inclusive of leaf laminae, in order to derive a leaf age based on known lengths of growth intervals in the species (Stark et al., 1998). Leaf age was estimated by assuming an annual growth interval of $0.25 \mathrm{~mm}$ after subtracting the measured distance from the point of attachment to the shoot apex to account for the extension of the shoot leaves above the apical meristem. This method yielded a mean age of $0.0,2.06,5.66$, and $11.60 \mathrm{yr}$ for juvenile, green, yellow-green, and brown leaves, respectively.

Growth chamber-Soil was collected from the native habitat, sieved through a $500 \mu \mathrm{m}$ mesh, dry autoclaved for $60 \mathrm{~min}$ at $132^{\circ} \mathrm{C}$, and apportioned into $160 \mathrm{mini}$ petri dishes ( $35 \mathrm{~mm}$ inner diameter) to a level about half filled (substrate depth $=4-5 \mathrm{~mm}$ ). Distilled water was applied to the edge of the dish wetting the entire surface, and the water level drawn down to the soil surface using a dry towelette. Each leaf was immediately placed on the substrate, adaxial surface up, in the center of the petri dish (one leaf per dish).

Growth chamber settings were a 12 -h photoperiod and day/night temperatures of $20^{\circ} / 8^{\circ} \mathrm{C}$, approximating winter/early spring conditions in the Mojave Desert (National Weather Service, 1994) and consistent with physiological optima for a variety of xeric and mesic bryophytes from USA and UK (Furness and Grime, 1982; Alpert and Oechel, 1987). Light intensity ranged from 89 to $128 \mu \mathrm{mol} \cdot \mathrm{m}^{-2} \cdot \mathrm{s}^{-1}$ on the upper shelf and from 33 to $44 \mu \mathrm{mol} \cdot \mathrm{m}^{-2}$ $\cdot \mathrm{s}^{-1}$ on the lower shelf (PAR sensor, LI-COR LI-250, Lincoln, Nebraska, USA), with higher readings in the center and lower readings in the corners. These light levels approximate the shaded, north-facing shrub microsites beneath shrub canopies where $S$. caninervis grows (L. R. Stark, unpublished data). Dishes were moved from one shelf to a random position on the other shelf every $7 \mathrm{~d}$. Photographs were taken using both a digital camera and a $35-\mathrm{mm}$ camera, each mounted on a dissecting microscope. Relative humidity in the chamber was approximately $60-70 \%$ for the duration of the experiment.

Daily through day 14 , leaves were examined for the presence of secondary protonemata (Fig. 2) by inspection up to $60 \times$ using a dissecting microscope. If present, the protonemal emergent point was noted as occurring in the apical, medial, or basal third of the leaf. Distinguishing any fungal hyphae (which appeared briefly during the first and second weeks of the experiment) from protonemata was not difficult: protonemal filaments are up to three times wider, are irridescent, and soon become photosynthetic green or rhizoidal brown in color. Leaves were inspected for protonemata every other day from day 14 through day 28 and on a weekly basis after day 28 for protonemal presence, shoot number (gametophores; Fig. 3), and Munsell tissue color. On days 11 and 12, leaves not producing secondary protonemata were nudged gently to detect the presence of rhizoidal filaments extending directly into the substrate and thus not visible from above: 10 leaves had produced rhizoids in this manner, with three having substantial rhizoid penetration. Rhizoids on these three were estimated to have regenerated $3 \mathrm{~d}$ earlier, while the others were taken as having regenerated on the day of nudging. Distilled water was 
1
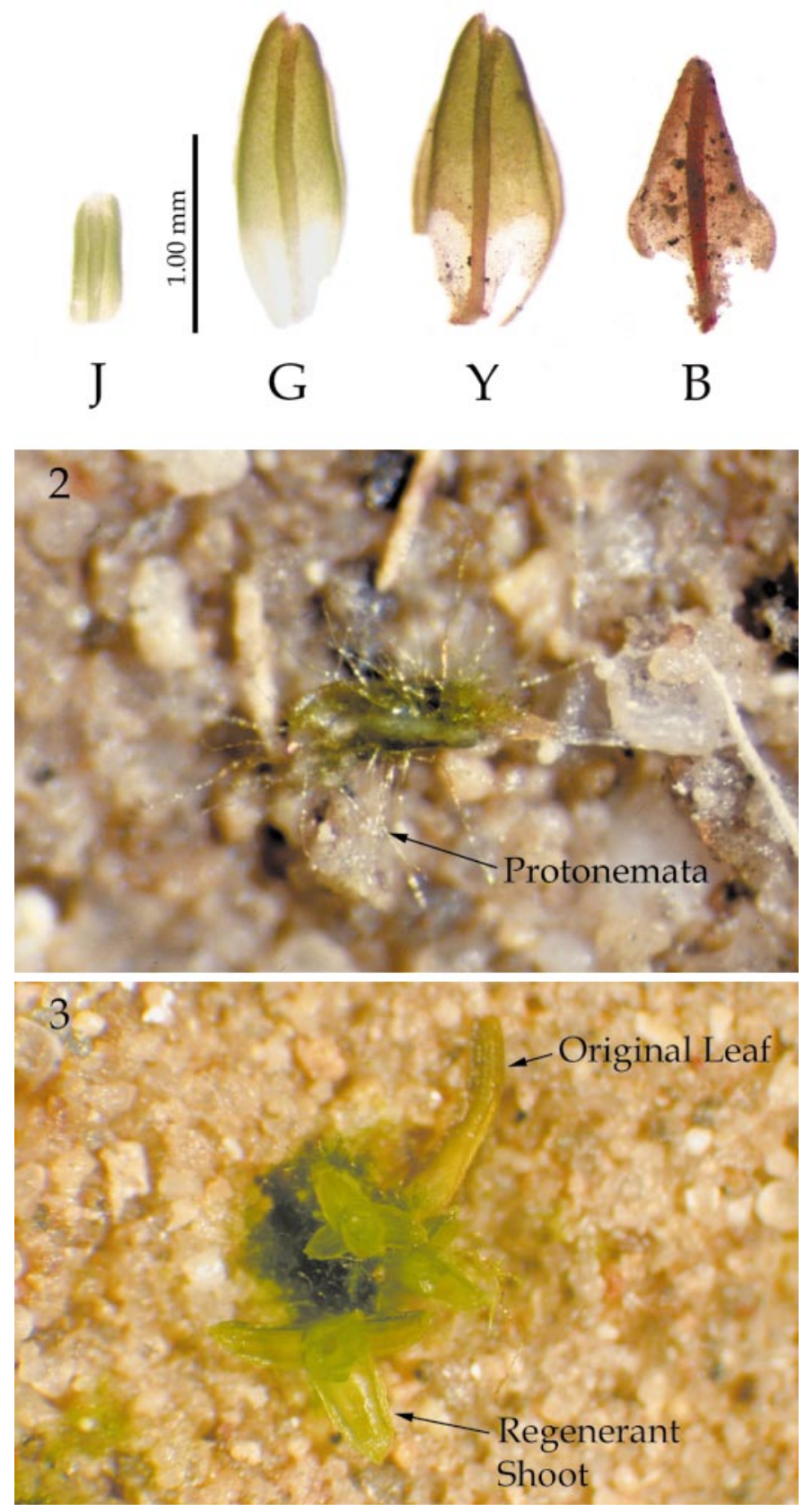

Figs. 1-3. Leaf age classes and regeneration in Syntrichia caninervis. 1. Photograph of juvenile $(\mathrm{J})$, green $(\mathrm{G})$, yellow-green $(\mathrm{Y})$, and brown $(\mathrm{B})$ leaves. 2. Photograph of protonemal emergence (female juvenile leaf, day 20). 3. Photograph of shoot emergence (three shoots from a female green leaf, day 56).

added to each dish on a weekly basis, bringing the water level up to the surface of the soil to continuously hydrate the detached leaves.

At the conclusion of the experiment $(58 \mathrm{~d})$, the linear distance from the original leaf to the furthest extent of protonemal growth was determined by measuring the distance on a digital image of the leaf, using image analysis software, to the nearest $0.01 \mathrm{~mm}$. Determination of the final biomass produced by each regenerating leaf was accomplished by (1) carefully removing the above- and belowground portions of the leaf/shoot/protonema/rhizoid complex (hereafter called the protonemal complex), maintaining organic connec- tions as much as possible, (2) immersing the protonemal complex in $2 \mathrm{~mL}$ of distilled water and swirling for $15 \mathrm{~s}$ to remove substrate particles, (3) placing the protonemal complex on a microscope slide and manually teasing the remaining larger substrate particles away, (4) rewashing in $2 \mathrm{~mL}$ of distilled water for $15 \mathrm{~s}$, (5) briefly blotting the cleaned protonemal complex on a dry towelette to remove excess water before placing it into a microenvelope constructed of weighing paper (to reduce sticking of tissues to the envelope when dry), (6) after air-drying, drying the complex to constant mass at $40^{\circ} \mathrm{C}$ for 3 $\mathrm{d}$, and (7) weighing using a microbalance to the nearest microgram.

Statistics-Analyses were performed to test for a relationship of sex and age with (1) the time to emergence of protonema, (2) rate of protonemal extension, (3) frequency of shoot production, (4) number of shoots produced, (5) time to shoot production, and (6) rate of biomass accumulation. For emergence (initial regeneration), we used a two-way analysis of variance to determine the effect of age, sex, and the interaction of age and sex on protonemal emergence time. Tukey's student range test was used to compare age class means. Extension rate for each plant was determined as the size (in millimeters) of the protonema divided by the number of days from emergence to the time the size data were taken. We used a two-way analysis of variance to determine the effects of age, sex, and the interaction of age and sex on protonemal growth rate. Tukey's student range test was used to compare age class means. Shoot production was treated in two ways. First, for the frequency of shoot production, we used log-linear analysis to determine if shoot production at day 28 and day 56 of the leaf was associated with leaf age (juvenile, green, yellow-green, and brown) and sex (female and male, i.e., leaf age and sex were considered explanatory variables for shoot production). An association was indicated by a significant interaction between shoot production and one or both of these factors (sex or leaf age). The statistical significance of an interaction was determined by assessing the change in the $\log$ likelihood ratio $\left(G^{2}\right)$ after addition or deletion of that term from the model (Sokal and Rohlf, 1995). This analysis was accomplished using categorical data analysis (CATMOD procedure, SAS, 1994). Second, for the number of shoots, we used a two-way analysis of variance to determine the effects of age, sex, and shoot production at day 56 for those leaves that produced shoots. Day 28 was not used because the range in shoot number was small. Only two age categories (juvenile and green leaves) were in this analysis because the older leaf ages (yellow-green and brown leaves) had a low probability of shoot production and thus their sample sizes were small $(n=3$ and $n=1$, respectively). Because of the low sample sizes in the two older classes, only juvenile and young leaves were used in the analysis on the effect of age and sex on time to first shoot production.

Rate of biomass increase was assumed to be linear and was estimated as the change in mass from initial to day 58 divided by the number of days since protonemal emergence. Initial biomass for each leaf age class was estimated from weighing at least 20 leaves of each leaf age class at one time. These initial masses were $0.003 \mathrm{mg}, n=20$ for juvenile leaves; $0.014 \mathrm{mg}$, $n=37$ for green leaves; $0.011 \mathrm{mg} n=44$ for yellow-green leaves; 0.006 $\mathrm{mg}, n=29$ for brown leaves. All statistical analyses were performed using the Statistical Analysis System (SAS, 1994).

\section{RESULTS}

Leaf viability and time to protonemal emergence-Nearly all of the juvenile $(100 \%)$, green $(98 \%)$, and yellow-green (98\%) leaves regenerated through the production of secondary protonemata. Brown leaves had a reduced level of regeneration (88\%): three female and four male leaves died (Table 1). There was no age $\times$ sex interaction effect on time to emergence. There was a strong age effect, with younger age classes having shorter mean times to emergence (juvenile $=7 \mathrm{~d}$, green $=9$ d) than older age classes (yellow-green $=22 \mathrm{~d}$, brown $=31$ d), and the two older age classes differed from each other (Table 2, Fig. 4). There was a weak sex effect (Table 2), with males emerging more quickly than females, the difference be- 
TABLE 1. Leaf viability (as the number of leaves producing secondary protonemata after $56 \mathrm{~d}$ in the growth chamber) of Syntrichia caninervis as a function of leaf age (position and color) and leaf gender. "Yellow" refers to yellow-green leaves.

\begin{tabular}{lcccc}
\hline \hline & Juvenile & Green & Yellow & Brown \\
\hline Regenerating & & & & \\
Male & 20 & 20 & 20 & 17 \\
Female & 20 & 19 & 19 & 18 \\
Total & 40 & 39 & 39 & 35 \\
Nonregenerating & & & & \\
Male & 0 & 0 & 0 & 3 \\
Female & 0 & 1 & 1 & 2 \\
Total & 0 & 1 & 1 & 5 \\
\hline
\end{tabular}

tween the sexes within age class ranging from $0.30 \mathrm{~d}$ for the youngest age class to $6.78 \mathrm{~d}$ for the oldest tested age class. However, three female data points were outliers as determined by the Dixon's test (Sokal and Rohlf, 1995). These females had relatively long times to emergence compared to other females in their age class. When these data points were removed from the analysis, sex was not significant and the mean emergence time with the relevant age class tended to be higher in male compared to female leaves.

Location along leaf of regenerant protonema-The position from which secondary protonemata originated varied with the age of the leaf, but not with gender. Juvenile leaves tended to produce protonemata from the medial and basal portions (19 medial, 15 basal, one medial-basal, five apical), while green leaves exhibited nearly uniform basal emergence (38 of 39). Yellow-green leaves tended to produce protonemata from the apical region of the leaf (17 of 39) with some basal production (14 of 39), and brown leaves regenerated most commonly from the medial portion of the leaf (21 of 35). Regarding basal regeneration, we did not distinguish between costal and lamina regeneration, but regeneration from the costal base was more frequent.

Protonemal extension-The extension of protonemal filaments from the edge of the leaf, measured as the linear distance from the leaf edge to the farthest reach of a protonemal filament, was dependent upon leaf age but not leaf gender (Table 3). The juvenile age class grew faster than the two older age classes (Fig. 5). There were no sex or age $\times$ sex interaction effects. In addition to the seven leaves that died, 20 male and 25 female leaves had no measurable protonemal extension.

Shoot production-Frequency of shoot production-Most shoots initially appeared directly from the detached leaf tissue and then later from protonemata in the vicinity of the leaf.

TABLE 2. Analysis of variance of the effect of age and sex on the time to protonemal emergence from leaves in Syntrichia caninervis. Data were square-root transformed prior to analysis.

\begin{tabular}{lrrl}
\hline \hline \multicolumn{1}{c}{ Source } & df & \multicolumn{1}{c}{$F$} & \multicolumn{1}{c}{$P$} \\
\hline Sex & 1 & 3.43 & 0.066 \\
Age & 3 & 79.21 & 0.0001 \\
Sex $\times$ age & 3 & 0.51 & 0.6739 \\
Error & 145 & & \\
\hline
\end{tabular}

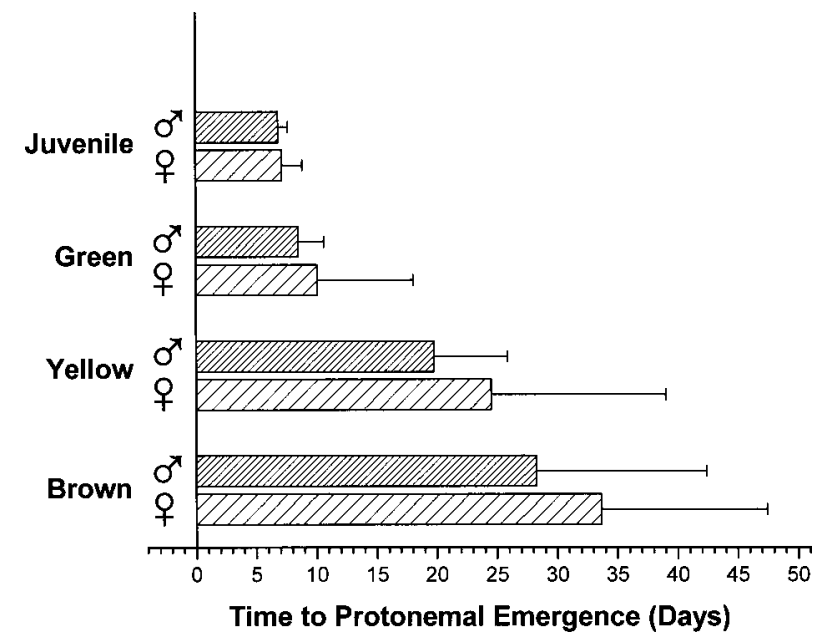

Fig. 4. Time to first protonemal emergence from leaves as a function of leaf age and leaf sex in Syntrichia caninervis (means \pm 1 SD). The two younger age classes did not differ from one another, the two older age classes differed from one another, and the younger age classes differed from the older age classes (Tukey's test).

While more leaves had produced shoots by day 56 than day 28 (45 vs. 25), the significant patterns were similar, so we report only data from day 56 . There was an association between sex and shoot production and an association between age and shoot production. For each of these two explanatory variables, the associations were significant with or without controlling for the other explanatory variable (Table 4). There was no interaction between age and sex and the ability to produce shoots. Overall, regenerated brown leaves were least likely to produce shoots $(2.9 \%, n=35)$, followed by regenerated yellow-green leaves $(7.7 \%, n=39)$, followed by regenerated green leaves $(41.0 \%, n=39)$, and followed by regenerated juvenile leaves $(62.5 \%, n=40)$. Compared to female leaves, male leaves were less likely to produce shoots (21.1\%, $n=76$ vs. $37.6 \%, n=77$; Fig. 6).

Shoot number and time to shoot production-On day 56, the number of shoots on leaves with shoots ranged from 1 to 8. For the two tested ages class (juvenile and green leaves), females produced more shoots than males $(2.63 \pm 0.34, n=$ 27 vs. $1.50 \pm 0.17, n=14$; mean \pm SE) and green leaves produced more shoots than the younger juvenile leaves (3.12 $\pm 0.50, n=16$ vs. $1.68 \pm 0.17, n=25$; see Table 5). There were no age or sex effects on time to shoot production (analysis not shown).

Biomass - Biomass accumulation rate varied as a function of leaf age, with younger leaves accumulating more biomass than the two oldest leaf classes (yellow-green and brown; Fig.

TABLE 3. Analysis of variance of the effect of age and sex on rate of protomemal extension from leaves in Syntrichia caninervis. Data were square-root transformed prior to analysis.

\begin{tabular}{lrcc}
\hline \hline \multicolumn{1}{c}{ Source } & df & $F$ & $P$ \\
\hline Sex & 1 & 0.04 & 0.8465 \\
Age & 3 & 6.87 & 0.0002 \\
Sex $\times$ age & 3 & 0.14 & 0.9382 \\
Error & 145 & & \\
\hline
\end{tabular}




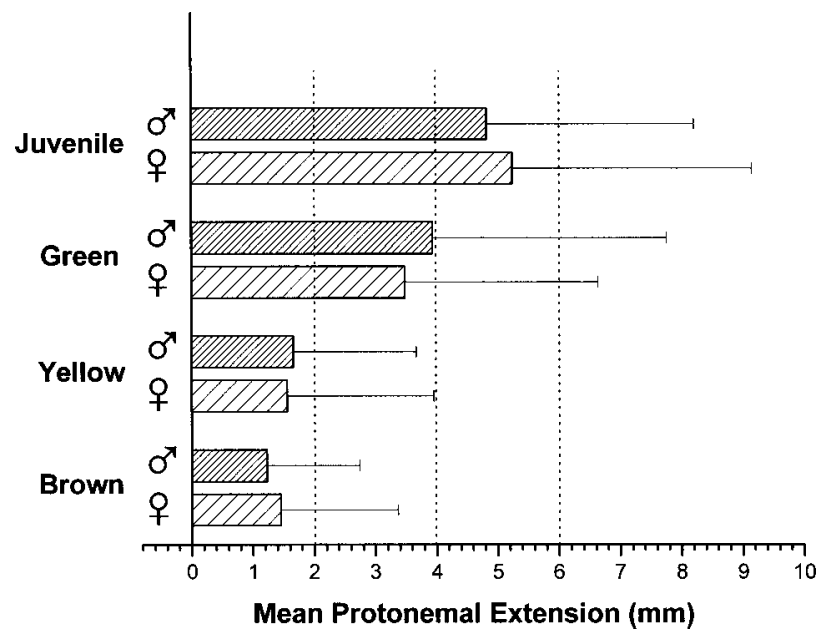

Fig. 5. Protonemal extension from regenerating leaves as a function of leaf age and leaf sex in Syntrichia caninervis, after $58 \mathrm{~d}$ in culture (means \pm $1 \mathrm{SD})$.

7, Table 6). Male leaves tended to have higher biomass accumulation rates but this tendency was not significant. All sexage categories, excepting juvenile males, produced less than $1.0 \mathrm{mg}$ of total biomass.

\section{DISCUSSION}

In the low elevation Mojave Desert, rains are brief, sporadic, and often nocturnal (Smith et al., 1997), and frosts or dew are rare and restricted to periods following winter rainstorms (L. R. Stark, personal observations). The period during which the plants are hydrated is very short, when the upper few centimeters of soil is hydrated. This duration is normally less than $1 \mathrm{wk}$ per storm, but on occasion it can extend to several weeks during the cooler months (Stark, 1997). The rough surface of the canopy of $S$. caninervis no doubt contributes to its rapid desiccation (Rice et al., 2001). Therefore, those plants that are able to capitalize on these brief hydrated periods by sending out protonemata from fragmented leaves and then sending up shoots from these protonemata, will have a colonizing advantage.

Protonemal emergence, position, and extension-Undetached leaves of most mosses do not produce protonemata in culture, with the implication that stems produce a substance that suppresses leaf regeneration (Keever, 1957; MacQuarrie and von Maltzahn, 1959; Lersten, 1961; Knoop, 1984). Detachment, rather than wounding, probably plays a more significant role in leaf regeneration (MacQuarrie and von Maltzahn, 1959). Both aerial (as in Grimmia; Keever, 1957) and subsurface protonemata were produced in Syntrichia, although the distinction between protonemata and rhizoids was not well developed: some filaments were at least partially photosynthetic despite growing beneath the soil surface. The pattern of leaf regeneration is probably unaffected by season of collection, although the rate of regeneration may be affected (Schröder et al., 1970).

The time to regeneration varies among species, but in general, leaf regeneration can be expected to commence within the first $10 \mathrm{~d}$ of culture. In the present study, earliest regeneration occurred on day 6 , but some leaves did not regenerate
TABLE 4. Results of log-linear analysis of leaf age class and sex associations with shoot production of Syntrichia caninervis. The statistical significance of an interaction is determined by assessing the change in the log-likelihood ratio, $G^{2}$, after addition or deletion of that term from the model. Models include all lower-order terms, e.g., the model $A S, O$ includes $A, S, O$, and $A S$, where $A=$ leaf type $(n=4), S=\operatorname{sex}(n=2)$, and $O=$ outcome or fate of the leaf $(n=2)$. See text for further descriptions of categorical data; the $G^{2}$ difference between the two models $\left(A S, O ; G^{2}=56\right)$ and $\left(A S, S O ; G^{2}=51.23\right)$ is the interaction term $S O ; G^{2}=4.77$, which is the effect of sex on shoot production. Analyses with the three interaction terms in the models test the effect of one explanatory variable while controlling for the other. $* P<0.05$, $* * P<0.01$, *** $P<0.001$

\begin{tabular}{|c|c|c|c|}
\hline Association tested with shoot production & Model & df & $G^{2}$ \\
\hline \multirow[t]{3}{*}{$\operatorname{Sex}(S O)$} & $A S, O$ & 7 & 56 \\
\hline & $-A S, S O$ & -6 & -51.23 \\
\hline & $S O$ & $\overline{1}$ & $4.77 *$ \\
\hline \multirow{3}{*}{ Age $(A O)$} & $A S, O$ & 7 & 56 \\
\hline & $-A S, A O$ & $-\underline{4}$ & -11.37 \\
\hline & $\overline{A O}$ & $\overline{3}$ & $44.63 * * *$ \\
\hline \multirow[t]{3}{*}{ Sex within age $(S O)$} & $A S, A O$ & 4 & 11.37 \\
\hline & $-A S, A O, S O$ & $-\underline{3}$ & -4.29 \\
\hline & $\overline{S O}$ & $\overline{1}$ & $\overline{7.08} * *$ \\
\hline \multirow[t]{3}{*}{ Age within sex $(A O)$} & $A S, S O$ & 6 & 51.23 \\
\hline & $-A S, S O, A O$ & $-\underline{3}$ & $-\underline{4.29}$ \\
\hline & $\overline{A O}$ & $\overline{3}$ & $4 \overline{6.94} * * *$ \\
\hline \multirow[t]{3}{*}{ Age and sex combinations $(A S O)$} & $A S, A O, S O$ & 3 & 4.29 \\
\hline & $-A S O$ & -0 & -0 \\
\hline & $\overline{A S O}$ & $\overline{3}$ & 4.29 \\
\hline
\end{tabular}

until day 56. Therefore, caution must be exercised in determinations of mortality or viability in experiments of this kind. Secondary protonemata emerged in 3-4 d in Mnium and $O c$ toblepharum (Schröder et al., 1970; Egunyomi, 1979), within a few days in a variety of UK species (Furness and Grime, 1982), after day 7 in Polytrichum (Gay, 1971), and uniformly by day 10 in Macromitrium (Une, 1985b). Compared to detached leaves, crushed gametophytic fragments required consistently more time ( $2 \mathrm{wk}$ ) for the 12 moss species cultured (Shaw, 1986).

As pointed out in Knoop (1984), a generalized pattern of

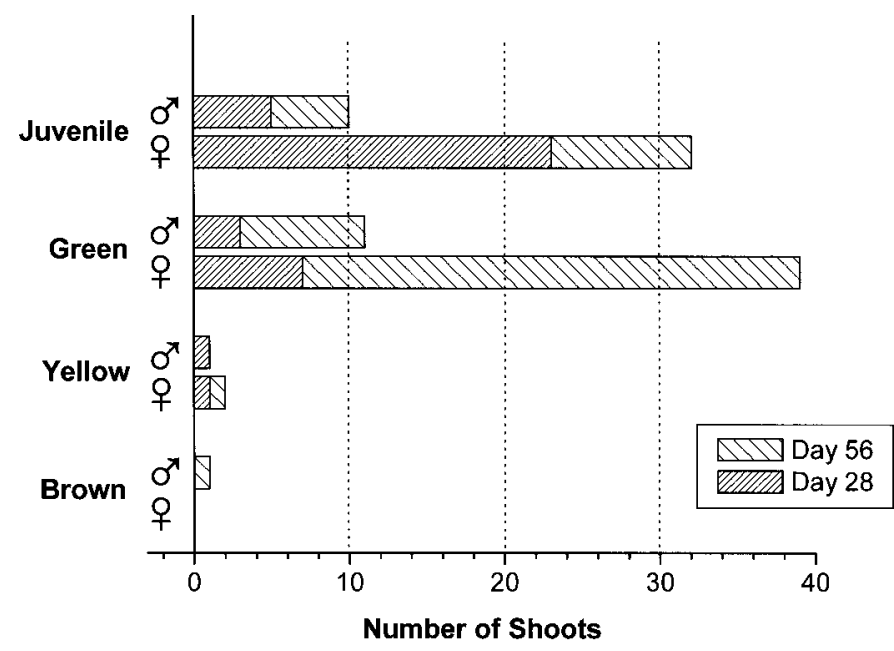

Fig. 6. Number of shoots produced by regenerating leaves as a function of leaf age and leaf sex in Syntrichia caninervis at two times. 
TABLE 5. Analysis of variance of the effect of age and sex on the number of shoots produced on leaves in Syntrichia caninervis. Only the youngest leaf age classes (juvenile and green) were used. Data were $\log$ transformed prior to analysis.

\begin{tabular}{lrrl}
\hline \hline Source & df & \multicolumn{1}{c}{$F$} & \multicolumn{1}{c}{$P$} \\
\hline Sex & 1 & 10.22 & 0.0028 \\
Age & 1 & 10.15 & 0.0029 \\
Sex $\times$ age & 1 & 1.50 & 0.228 \\
Error & 37 & & \\
\hline
\end{tabular}

the region of leaf regeneration among mosses is not clear. In $S$. caninervis, this position varied as a function of the age of the leaf, with younger leaves tending toward a basal regeneration and older leaves toward a more apical regeneration. An age effect was also found in Mnium; younger leaves regenerated only from the costa, whereas older leaves regenerated from the lamina (Schröder et al., 1970). Protonemal emergence may be basal, as exemplified in species of Mnium (base of the costa; Lersten, 1961) and Pleurozium (restricted to the alar region; Longton and Greene, 1979), or emergence may be marginal as in Tetraphis (Schneider and Sharp, 1962) or even predominantly apical in Polytrichum (costal zone underlying lamellae; Gay, 1971). Abaxial surfaces are most often implicated in protonemal origination from detached leaves (Lersten, 1961; Schröder et al., 1970), although the contact zone may supersede the surface (Schneider and Sharp, 1962). In the present study, leaves of $S$. caninervis were placed on their abaxial surface, and only adaxial protonemal emergence could be readily observed against the opaque sand.

The mean rate of protonemal growth in S. caninervis $(0.066$ $\mathrm{mm} / \mathrm{d}$; range $0.0-0.25 \mathrm{~mm} / \mathrm{d}$ ) was lower than the rates for two more mesic species studied. In Ceratodon, the proliferation rate was $0.29 \mathrm{~mm} / \mathrm{d}$ (recalculated from Shaw and Gaughan, 1993 ) and in Pleurozium, the rate was $0.13-0.16 \mathrm{~mm} / \mathrm{d}$ (recalculated from Longton and Greene, 1979).

Protonemata of $S$. caninervis have not been observed in the field (L. R. Stark, personal observations). However, in the desert, protonemata may only be visible when hydrated, which is rare. Among low elevation Mojave Desert populations of Tortula, Crossidium, and Grimmia, significant protonemal proliferation has been noted only once in the last $10 \mathrm{yr}$ (winter of 1994/1995), during which high precipitation caused the ground surface to remain continuously moist for 7-8 wk (Stark, 1997). When extracting the protonemal complexes from the soil, adhesion of the protonemata to the soil translated into a long and arduous process of repeated washings in order to cleanse the protonemata of sand granules. Thus, the positive contributions of cyanobacteria in enhancing soil stability, moisture retention, and fertility of desert soils (Belnap and Gardner, 1993) may well apply to moss protonemata.

Shoot production-The time from protonemal emergence to shoot production (or just the time to shoot production and the number of shoots) is critical in the desert, because the hydroperiod is normally very short. Shoot production from detached leaves of $S$. caninervis commenced on day 21 and was apparently much more rapid than regeneration rates observed from arctic Canadian mosses, many species of which exhibited an absence of shoot production even after 4.5 mo in culture (Miller and Ambrose, 1976). Similar to Syntrichia were both male and female plants of Macromitrium japonicum, for which detached leaves took $30 \mathrm{~d}$ to produce the first

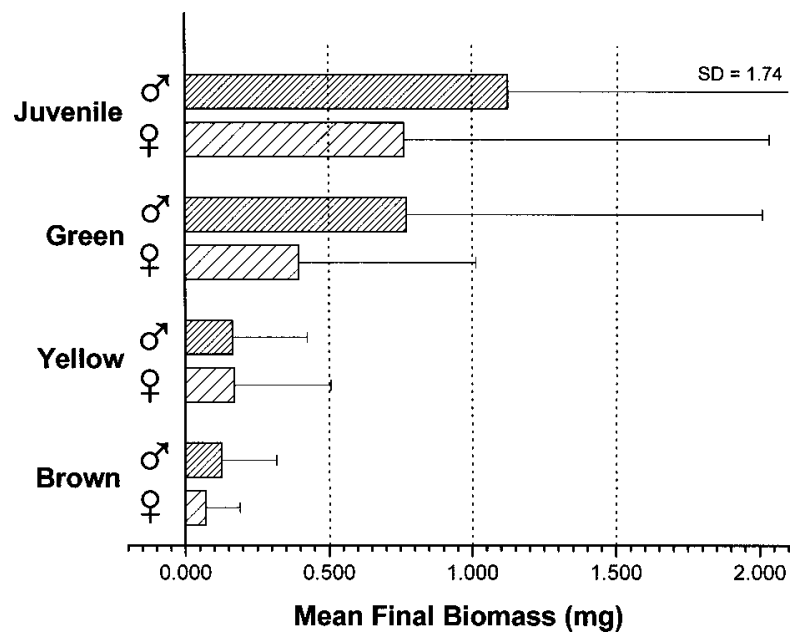

Fig. 7. Total dry biomass produced by regenerating leaves as a function of leaf age and leaf sex in Syntrichia caninervis at two times (means \pm 1 $\mathrm{SD}$, with SD for juvenile male indicated).

shoot (Une, 1985b). Protonemata derived from stems of Grimmia laevigata did not produce buds even after 6 mo (Keever, 1957). Thus, some species may rely on protonemal proliferation to cover a surface, prior to producing shoots. Such a protonemal mat may serve to anchor the shoots to the substrate more effectively, especially in rock-dwelling mosses. The first shoots produced most commonly develop directly from the leaf bases in Pleurozium (Longton and Greene, 1979), Syntrichia, and in Macromitrium (Une, 1985b).

Leaf age and color-In every category monitored, younger leaves (juvenile, green) of $S$. caninervis responded with faster and more productive regeneration than older leaves (yellowgreen, brown). Juvenile (and green) leaves produced secondary protonemata more quickly, resulting eventually in further protonemal extension and ultimately in more shoots and total biomass. Juvenile and green leaves were similar in response among most variables measured, as were yellow-green and brown leaves; thus, two general age classes existed. This experiment demonstrated that leaves up to $12 \mathrm{yr}$ of age are capable of regenerating. Older leaves have not yet been tested, but pilot trials using stem tissue of $S$. caninervis indicates that tissue up to and over two decades old is capable of regeneration. Longton and Schuster (1983) and Longton (1988) also noted that stems of several species, when placed horizontally on media, exhibited budding and protonemal emergence from tissue several years old. Regenerating tissue and younger leaves of $S$. caninervis also tended to resist fungal attack, while brown leaf tissue was more vulnerable to fungal attack. Nevertheless, even while under fungal attack, several brown leaves generated secondary protonemata and "escaped" the fungi.

TABLE 6. Analysis of variance of the effect of age and sex on biomass accumulation rate in Syntrichia caninervis. Data were log transformed prior to analysis.

\begin{tabular}{lrcl}
\hline \hline \multicolumn{1}{c}{ Source } & df & \multicolumn{1}{c}{$F$} & \multicolumn{1}{c}{$P$} \\
\hline Sex & 1 & 0.30 & 0.58 \\
Age & 3 & 5.66 & 0.0011 \\
Sex $\times$ age & 3 & 0.65 & 0.5847 \\
Error & 141 & & \\
\hline
\end{tabular}


Younger leaves regenerated more rapidly than older leaves in Polytrichum (Gay, 1971), Pleurozium (Longton and Greene, 1979), and Tetraphis (Schneider and Sharp, 1962). Similarly in Grimmia, photosynthetic rates were several times more rapid in the younger apical shoots than in brown proximal shoots: 2.63 vs. $0.34 \mathrm{mg} \mathrm{CO}_{2} \cdot \mathrm{g}^{-1} \cdot \mathrm{h}^{-1}$, green vs. brown shoots (Alpert and Oechel, 1985). However, regeneration from basal leaves in Funaria (Bopp, 1955) exceeded that in even the most apical leaves, a pattern also noted in Atrichum (Gemmell, 1953) and Mnium (Schröder et al., 1970; Newton, 1972). These latter three genera are likely short-lived, with even basal leaves only one to a few years old. Two explanations exist regarding these two patterns, with both reflecting age: one of position in relation to the stem apex and one reflecting leaf senescence (Knoop, 1984).

Leaves lose their photosynthetic capacity and their ability to withstand desiccation as they age (Egunyomi, 1979; Alpert, 2000), with G2 segments (leaves 2-3 yr old) normally having a net carbon loss in Hylocomium and Polytrichum (Callaghan et al., 1978). In Crossidium, partially chlorophyllose leaves occurred in the G1 interval (leaves 1-2 yr old) and had entirely senesced by $\mathrm{G} 2$; thus, photosynthetic capacity greatly decreased by the second year and was entirely absent by the third year (Stark and Delgadillo, 2003). On the contrary, in S. caninervis leaves up to $6 \mathrm{yr}$ of age (G5) were at least partially photosynthetic, and even the majority of entirely brown leaves estimated to be $12 \mathrm{yr}$ old were capable of regeneration.

Leaf coloration, taken alone, was not a sound measure of leaf viability, because 35 of 40 "brown" leaves (initial color of 2.5 Y 7/8; Wilde and Voigt, 1977) eventually produced secondary protonemata. Why a viable tissue would "pause" so long relative to younger leaves is puzzling, and perhaps relates to the degradation of the cytoplasmic machinery in older cells. In more desiccation-sensitive species, color may be a more reliable indicator of viability, as shown in the liverwort Bazzania (Sollows et al., 2001).

Sex dimorphisms-Variation in adult population sex ratios has been linked to sex-specific differences in life history in animals and plants. Among species with the ability to clonally expand, the most frequent prediction is that the sex in the majority will have higher levels of clonal expansion. This expectation is usually supported (see Introduction). However, this prediction might be an oversimplification, and more complex relationships between clonal expansion traits and adult population sex ratio may exist. This complexity is indicated by examples of species/populations with the minority sex having a clonal advantage and also by examples in which, compared to one sex, the other sex has a higher capacity of clonal expansion in one trait and a lower level in another trait. Additionally, a recent model suggests that local population sex ratio in dioecious clonal species is not stable, leading to unisexual populations (McLetchie et al., 2002).

In animals, skewed sex ratios can be explained by differences in clonal vigor between the sexes (McGovern, 2002). Among clonal dioecious seed plants, male-biased population sex ratios are common, and male plants generally invest more in clonal growth than do female plants (Putwain and Harper, 1972; Lovett Doust and Lovett Doust, 1988). However, there are exceptions to this pattern (Grant and Mitton, 1979; Sakai and Sharik, 1988). Bryophyte species and populations tend to be female-biased (Stark et al., 1998 and references therein), and there have been several attempts to demonstrate that fe- males have a clonal expansion advantage but few studies were successful. Relative to male plants, female plants of Mnium undulatum (Newton, 1972) and Sphaerocarpos texanus (McLetchie, 1992) have a higher capacity for clonal expansion and survival, respectively. However, inconsistent patterns occur: detached male leaves of Pleurozium schreberi grown on moist filter paper produced more than twice as many shoot buds than female leaves (Longton and Greene, 1979), and shoot formation from germinated spores did not differ between males and females in Ceratodon purpureus (Shaw and Beer, 1999).

There are several examples in which female plants have a higher potential for clonal expansion in one trait and male plants in another. Male leaves of Macromitrium japonicum produced more shoots per regenerated leaf than female leaves, while female sporelings produced their first shoot $20 \mathrm{~d}$ faster than male sporelings (Une, 1985b). In Ceratodon purpureus, females have larger ramets and produce larger clones, while male protonemata produce more ramets, leading to a higher shoot density for males (Shaw and Gaughan, 1993). In Pogonatum and Atrichum, male plants grew more slowly and over a longer period than female plants, with female plants growing faster over shorter periods (Imura, 1994). Males of Marchantia inflexa produce more gemmae than females, whereas females have higher growth rates and produce more meristematic tips (McLetchie and Puterbaugh, 2000). Recently, a simulation model on sex ratio dynamics using field and laboratory parameter values for Marchantia inflexa demonstrated the connection between sex-specific life histories and local population sex ratios that did not allow for coexistence (McLetchie et al., 2002).

The results from this study suggest that $S$. caninervis belongs to the latter group of studies; that is, females have higher potential in some clonal traits and male plants have a higher potential in other clonal traits. Females produce more shoots and produce them more frequently than males. That shoot production was higher in females and that biomass did not differ between male and female plants (there was an insignificant tendency for male plants to have higher biomass accumulation rates than female plants) indicates that there are sex-specific allocation differences. Namely, compared to females, male tissue might be denser or, more likely, male plants have a more developed underground protonemal complex. Through shoot production, an individual can capture space that is adjacent to the source of the new shoot. Through protonemal extension, an individual can capture space that is farther than the source. Thus, female plants, with greater capacity for shoot production, could be more locally competitive compared to males. Likewise males, with their higher capacity for protonemal extension, may be more competitive at farther distances. A similar argument was made for Marchantia inflexa (McLetchie and Puterbaugh, 2000). One possible population consequence of these growth patterns is that while female plants produce more shoots in the short term, males might produce higher numbers of shoots in the long term if protonemata production is positively associated with shoot production. We did not assay secondary shoot production that might have occurred after the experiment was terminated.

Experimental vs. field conditions-Some caveats are in order regarding the assumption that findings from growth chamber studies carry over into field conditions in that field conditions are more extreme than the growth chamber. First, when 
plants from the field are directly cultured, as opposed to using regenerant plants, plasticity in plant responses might occur because of local microhabitat site effects that carried over to the growth chamber. Second, when near-ideal conditions of light and hydration are used, growth rate is probably faster than in the field because the hydroperiod is uninterrupted by drying (Dilks and Proctor, 1976; Hanslin et al., 2001). Thus, under the experimental conditions, we probably observed much more rapid protonemal expansion and shoot bud production than under field conditions except during a very unusual winter (observed only once in the last $10 \mathrm{yr}$ ). Third, given that several leaves of $S$. caninervis began regeneration on the last day of observation (day 56), it is possible that the seven leaves (of 160 ) that did not regenerate may yet be viable, as for example if emergence was not always reliably detected when rhizoids emerged (grew downward vertically) without protonemal emergence. Finally, in this experiment, leaves were taken from expressing males and expressing females. Given that males incur a much higher cost of sex expression in Syntrichia (Stark et al., 2000), leaf regeneration rates might reflect this cost as part of a carryover effect. That is, the superiority of females in regenerating stems from secondary protonemata may be related to the lower cost of sex expression (relative to males) in the parental plants. One manifestation of this might be a higher nutrient status among female compared to male leaves. Similarly, nonexpressing males and females would be expected to regenerate at the highest rates. Unfortunately, at present we do not have a sex determination marker that would allow the determination of gender in the absence of sex expression.

Future directions-In S. caninervis, specialized asexual propagules are unknown and sexual reproduction is rare. Therefore, individuals of this species are expected to rely heavily upon fragmentation of the adult phases of the gametophyte to disperse, colonize, and increase population density. Females appear to have a regenerational advantage compared to males by producing more shoots more quickly. However, higher protonemal production by male plants relative to female plants could result in delayed shoot production in males. Whether this potential delay in shoot production can result in a clonal advantage for males needs to be addressed with longterm empirical studies or mathematical simulations. Plants in the field doubtless experience cycles of hydration and desiccation not experienced in the present experiment. The next steps are to test if these regenerant plants (male and female) and tissue types (shoots and leaves vs. protonemata) differ in their ability to tolerate the inevitable cycles of desiccation stress that will accompany the effective regeneration of the colony. Therefore, we will expose both field-collected and regenerant male and female plants to water stress and examine survivability of regenerant tissue. Other avenues of research to investigate are potential sex dimorphisms in wet and dry high temperature stress.

\section{LITERATURE CITED}

Alpert, P. 2000. The discovery, scope, and puzzle of desiccation tolerance in plants. Plant Ecology 151: 5-17.

AlPert, P., AND W. C. OECHEL. 1985. Carbon balance limits the microdistribution of Grimmia laevigata, a desiccation-tolerant plant. Ecology 66: $660-669$.

Alpert, P., AND W. C. OEChEl. 1987. Comparative patterns of net photosynthesis in an assemblage of mosses with contrasting microdistributions. American Journal of Botany 74: 1787-1796.
Belnap, J., AND J. S. GARDNER. 1993. Soil microstructure in soils of the Colorado Plateau: the role of the cyanobacterium Microcoleus vaginatus. Great Basin Naturalist 53: 40-47.

Bopp, M. 1955. Über die Regeneration an Blättern von Laubmoosen. Revue Bryologique et Lichénologique 24: 49-58.

Bowker, M. A., L. R. Stark, D. N. Mcletchie, And B. D. Mishler. 2000 Sex expression, skewed sex ratios, and microhabitat distribution in the dioecious desert moss Syntrichia caninervis (Pottiaceae). American Journal of Botany 87: 517-526.

Callaghan, T. V., N. J. Collins, and C. H. Callaghan. 1978. Photosynthesis, growth and reproduction of Hylocomium splendens and Polytrichum commune in Swedish Lapland. Oikos 31: 73-88.

Dilks, T. J. K., AND M. C. F. PROCTOR. 1976. Effects of intermittent desiccation on bryophytes. Journal of Bryology 9: 249-264.

During, H. J. 1990. Clonal growth patterns among bryophytes. In J. van Groenendael and H. de Kroon [eds.], Clonal growth in plants: regulation and function, 153-176. SPB Academic Publishing, The Hague, Netherlands.

Egunyomi, A. 1979. Autecology of Octoblepharum albidum in western Nigeria. II. Phenology and water relations. Nova Hedwigia 31: 377-389.

Eppley, S. M., L. M. Stanton, AND R. K. Grossberg. 1998. Intrapopulational sex ratio variation in the salt grass Distichlis spicata. American Naturalist 152: 659-670.

EsCARre, J., AND C. Houssard. 1991. Changes in sex ratio in experimental populations of Rumex acetosella. Journal of Ecology 79: 379-387.

Flowers, S. 1973. Mosses: Utah and the West. Brigham Young University Press, Provo, Utah, USA.

Furness, S. B., AND J. P. GRIME. 1982. Growth rate and temperature responses in bryophytes I. An investigation of Brachythecium rutabulum. Journal of Ecology 70: 513-523.

Gallego, M. T. 2002. Pottiaceae: Syntrichia. In M. J. Cano, R. M. Ros, and J. Guerra [eds.], Flora briofítica Ibérica, 1-31. Sociedad Española de Briología, Murcia, Spain.

GAY, L. 1971. Correlative systems controlling regeneration on gametophytes of Polytrichum juniperum Willd. Zeitschrift fuer Pflanzenphysiologie 66: $1-11$.

Gemmell, A. R. 1953. Regeneration from the leaf of Atrichum undulatum (Hedw.) P. Beauv. Transactions of the British Bryological Society 2: 203213.

Grant, M. C., And J. B. Mitton. 1979. Elevational gradients in adult sex ratios and sexual differentiation in vegetative growth rates of Populus tremuloides Michx. Evolution 33: 914-918.

Hanslin, H. M., S. Bakken, And B. Pedersen. 2001. The impact of watering regime and ambient relative humidity on the effect of density on growth in two boreal forest mosses, Dicranum majus and Rhytidiadelphus loreus. Journal of Bryology 23: 43-54.

Husband, B. C., AND S. C. H. BARRETT. 1996. A metapopulation perspective in plant population biology. Journal of Ecology 84: 461-469.

ImURA, S. 1994. Phenological study in two dioecious mosses, Atrichum rhystophyllum (C. Müll.) Par. and Pogonatum inflexum (Lindb.) Lac. Journal of the Hattori Botanical Laboratory 76: 105-114.

KeEver, C. 1957. Establishment of Grimmia laevigata on bare granite. Ecology 38: 422-429.

KNOOP, B. 1984. Development in bryophytes. In A. F. Dyer and J. G. Duckett [eds.], The experimental biology of bryophytes, 143-176. Academic Press, London, UK

Korpelainen, H. 1992. Patterns of resource allocation in male and female plants of Rumex acetosa and R. acetosella. Oecologia 89: 133-139.

Kumar, D., N. Manocha, And P. Tiwari. 2000. On the regeneration in Calobryales. Geophytology 29: 81-87.

LERSTEN, N. 1961. A comparative study of generation from isolated gametophytic tissues in Mnium. Bryologist 64: 37-47.

Longton, R. E. 1988. The biology of polar bryophytes and lichens. Cambridge University Press, Cambridge, UK.

Longton, R. E. 1990. Sexual reproduction in bryophytes in relation to physical factors of the environment. In R. N. Chopra and S. C. Bhatla [eds.], Bryophyte development: physiology and biochemistry, 139-166. CRC Press, Boca Raton, Florida, USA.

Longton, R. E., AND S. W. GREENE. 1979. Experimental studies of growth and reproduction in the moss Pleurozium schreberi (Brid.) Mitt. Journal of Bryology 10: 321-338.

Longton, R. E., And R. M. Schuster. 1983. Reproductive biology. In R. 
M. Schuster [ed.], New manual of bryology, vol. 1, 386-462. Hattori Botanical Laboratory, Nichinan, Japan.

LovetT Doust, J., AND L. LovetT Doust. 1988. Modules of production and reproduction in a dioecious clonal shrub, Rhus typhina. Ecology 69: $741-750$.

MacQuarrie, G., and K. E. von Maltzahn. 1959. Correlations affecting regeneration and reactivation in Splachnum ampullaceum (L.) Hedw. Canadian Journal of Botany 37: 121-134.

MCGovern, T. M. 2002. Sex-ratio bias and clonal reproduction in the brittle star Ophiactis savignyi. Evolution 56: 511-517.

McLetchie, D. N. 1992. Sex ratio from germination through maturity and its reproductive consequences in the liverwort Sphaerocarpos texanus. Oecologia 92: 273-278.

Mcletchie, D. N., G. García-Ramos, And P. H. Crowley. 2002. Local sex-ratio dynamics: a model for the dioecious liverwort Marchantia inflexa. Evolutionary Ecology 15: 231-254.

McLetchie, D. N., AND M. N. Puterbaugh. 2000. Population sex ratios, sex-specific clonal traits and tradeoffs among these traits in the liverwort, Marchantia inflexa. Oikos 90: 227-237.

Miller, N. G., AND L. J. H. Ambrose. 1976. Growth in culture of windblown bryophyte gametophyte fragments from arctic Canada. Bryologist 79: 55-63.

National Weather Service. 1994. Local climatological data, monthly summaries. McCarren International Airport, Las Vegas, Nevada, USA.

Newton, M. E. 1972. Sex ratio differences in Mnium hornum Hedw. and M. undulatum Sw. in relation to spore germination and vegetative regeneration. Annals of Botany 36: 163-178.

Newton, A. E., AND B. D. Mishler. 1994. The evolutionary significance of asexual reproduction in mosses. Journal of the Hattori Botanical Laboratory $76:$ 127-145.

Popp, J. W., AND J. A. ReInARTZ. 1988. Sexual dimorphism in biomass allocation and clonal growth of Xanthoxylum americanum. American Journal of Botany 75: 1732-1741.

Putwain, P. D., AND J. L. Harper. 1972. Studies in the dynamics of plant populations. V. Mechanisms governing the sex ratio in Rumex acetosa and $R$. acetosella. Journal of Ecology 60: 113-129.

RAmSAY, H. P., AND G. K. BerRIE. 1982. Sex determination in bryophytes. Journal of the Hattori Botanical Laboratory 52: 255-274.

Rice, S. K., D. Collins, AND A. M. Anderson. 2001. Functional significance of variation in bryophyte canopy structure. American Journal of Botany 88: 1568-1576.

SAKAI, A. K., AND T. A. BuRrIs. 1985. Growth in male and female aspen clones: a twenty-five-year longitudinal study. Ecology 66: 1921-1927.

SAKAI, A. K., AND T. L. ShariK. 1988. Clonal growth of male and female bigtooth aspen, Populus grandidentata. Ecology 69: 2031-2033.

SAS. 1994. SAS/STAT user's guide, version 6, 4th ed., vol. I. SAS Institute, Cary, North Carolina, USA.

SCHNEIDER, M. J., AND A. J. SHARP. 1962. Observations on the reproduction and development of the gametophyte of Tetraphis pellucida in culture. Bryologist 65: 154-166.
SCHRÖDER, H., W. R. MÜlleR-StOll, AND J. ERDTMANN. 1970. Entstehung von Regeneraten an den Blättern von Mnium undulatum L. in Abhängigkeit von deren Insertion und vom Blattbezirk. Biochemie und Physiologie der Pflanzen 161: 542-559.

SHAw, J. 1986. A new approach to the experimental propagation of bryophytes. Taxon 35: 671-675.

Shaw, A. J., AND S. C. BEER. 1999. Life history variation in gametophyte populations of the moss Ceratodon purpureus (Ditrichaceae). American Journal of Botany 86: 512-521.

Shaw, A. J., AND J. F. Gaughan. 1993. Control of sex ratios in haploid populations of the moss, Ceratodon purpureus. American Journal of Botany 80: 584-591.

Smith, S. D., R. K. Monson, And J. E. Anderson. 1997. Physiological ecology of North American desert plants. Springer-Verlag, Berlin, Germany.

SOKAL, R. R., AND F. J. RoHLF. 1995. Biometry: the principles and practice of statistics in biological research, 3rd ed. W. H. Freeman, New York, New York, USA.

Sollows, M. C., K. A. Frego, AND C. Norfolk. 2001. Recovery of Bazzania trilobata following desiccation. Bryologist 104: 421-429.

STARK, L. R. 1997. Phenology and reproductive biology of Syntrichia inermis (Bryopsida, Pottiaceae) in the Mojave Desert. Bryologist 100: 13-27.

Stark, L. R., And C. Delgadillo M. 2003. Is Crossidium crassinerve (Pottiaceae) an annual moss? Observations on vegetative allocation and viability from Mojave Desert populations. Lindbergia 28: 3-13.

Stark, L. R., D. N. McLetchie, and B. D. Mishler. 2001. Sex expression and sex dimorphism in sporophytic populations of the desert moss Syntrichia caninervis. Plant Ecology 157: 183-196.

Stark, L. R., B. D. Mishler, and D. N. McLetchie. 1998. Sex expression and growth rates in natural populations of the desert soil crustal moss Syntrichia caninervis. Journal of Arid Environments 40: 401-416.

Stark, L. R., B. D. Mishler, And D. N. McLetchie. 2000. The cost of realized sexual reproduction: assessing patterns of reproductive allocation and sporophyte abortion in a desert moss. American Journal of Botany 87: $1599-1608$.

UNE, K. 1985a. Geographical distribution of male and female plants in species of Macromitrium Brid. (Musci: Orthotrichaceae) in Japan. Journal of the Hattori Botanical Laboratory 59: 515-521.

UNE, K. 1985b. Factors restricting the formation of normal male plants in the isosporous species of Macromitrium (Musci: Orthotrichaceae) in Japan. Journal of the Hattori Botanical Laboratory 59: 523-529.

Voth, P. D., AND K. C. HAMNER. 1940. Responses of Marchantia polymorpha to nutrient supply and photoperiod. Botanical Gazette 102: 169-205.

WiLDE, S. A., AND G. K. VoIGT. 1977. Munsell color charts for plant tissues. Kollmorgen Instruments, New Winsor, New York, USA.

Williams, S. L. 1995. Surfgrass (Phyllospadix torreyi) reproduction: reproductive phenology, resource allocation, and male rarity. Ecology 76: 1953-1970.

WyatT, R. 1994. Population genetics of bryophytes in relation to their reproductive biology. Journal of the Hattori Botanical Laboratory 76: 147-157. 